
\title{
BReserch S Suare \\ Quality of Life, Levels of Anxiety and Depression Among Sudanese Patients With Surgical Stoma in Khartoum State, Sudan.
}

\section{Razaz Mahde Esmaeel Musa}

University of Khartoum

Mugahid A Salih

University of Khartoum

Kamil M.A.Shaaban

University of Khartoum

Alnazeer Y. Abdelbagi ( $\nabla$ dr.alnazeer37@gmail.com )

University of Khartoum

\section{Research Article}

Keywords: quality of life, colostomy, ileostomy, stoma, FIQOL, HADS

Posted Date: March 8th, 2022

DOI: https://doi.org/10.21203/rs.3.rs-1307595/v2

License: (c) (i) This work is licensed under a Creative Commons Attribution 4.0 International License. Read Full License 


\section{Abstract}

Background: The objectives of this study are to assess the quality of life, levels of anxiety, and depression among Sudanese ostomates with special emphasis on sociodemographic data and ostomy-related data.

Methods: This is a facility-based cross-sectional study in Khartoum state between 2018 and 2019. 100 patients participated in the study with a response rate of 80 in seven hospitals throughout Khartoum state. Standardized fecal incontinence quality of life (FIQOL) and hospital anxiety and depression scale (HADS) questionnaires were used and data obtained were analyzed by multiple statistical tests to identify any group differences and associations to the sociodemographic data.

Results: Quality of life total score was found to be below the average. Depression scale scores at the average, and religious score account for the worst. While there is a strong correlation between the QOL subscales, there was no significant association between quality of life score and the sociodemographic data. Regarding anxiety and depression levels $51.3 \%$ of the participants are normal for anxiety level while $25 \%$ and $23.8 \%$ were borderline and abnormal respectively. For depression level, the score was $45 \%$ normal, $26.3 \%$ borderline and $28.8 \%$ were abnormal. neither some significant association nor subgroup differences were found regarding sociodemographic and ostomy-related data.

Conclusions: Respondents had a quality of life below the average and high levels of anxiety and depression. Religious and spiritual QOL is marginally influenced by the intestinal stoma, qualitative comments also lend insight to the spiritual aspect. this finding can assist in the provision of holistic care in our stoma patients.

\section{Background:}

A stoma could be defined as an opening that could be natural or surgically made to connect a viscus body organ with the exterior. This is usually made for a hollow organ (small intestine, large intestine, stomach, urinary bladder) within the abdomen. Two of the common procedures usually done in the gastrointestinal tract are ileostomy (small intestine stoma) and colostomy (large intestine stoma).

The first proper percutaneous colostomy was performed by Littre in 1710. After this, different surgeons started to practice this procedure with different techniques as medical sciences and technologies continue to develop. The history of stoma surgery goes a long way back to the 4th century B.C when the medical intervention for patients having abdominal pathologies for improving the quality of health of patients, specifically for patients suffering from colon cancers ${ }^{(1)}$.

There is an increase in abdominal conditions and diseases which require a stoma formation. Stomas are usually indicated for patients suffering from cancers, intestinal tuberculosis, enteric perforation, penetrating injuries, blunt trauma, inflammatory bowel disease, diverticulitis, bowel ischemia, radiation enteritis, fistula, incontinence, intestinal obstruction, and spinal cord injuries ${ }^{(2-4)}$. 
Patients with stomas face many problems, both physical and psychological. Leakage caused by failure of adhesive or bag welds, ballooning of bags, poor siting, and difficulty in keeping bags in place are some of the daily problems, early complication includes metabolic derangements, skin irritation, ischemia, and stoma retraction ${ }^{(5-7)}$.

Stoma produces social, domestic, and psychological upsets. Anxiety and embarrassment over a stoma may alter lifestyle, including the ability to work, desire to travel, and overall self-image. The way patients feel about the changes in their bodies can affect their behavior toward family and friends. Some patients have initial problems with diet and clothing. Problems with sex life also occur ${ }^{(8-10)}$.

A person's body image and sexuality are major factors in determining the effect of a stoma on the quality of life. A person's sexuality is closely associated with their body image and feelings. A lot of ostomates were found to have impaired sexual functions. Their concern is that their sexual attractiveness has been diminished. A lot of relationships had been failed due to stoma $(5,11)$.

Few studies have been conducted to seek any evidence of QOL among Sudanese stoma patients. Given that intestinal perforations are fairly in swank in our country and many patients are subjected to stoma after surgery. This apparent lack of research interest is surprising because the stoma surgery started very early in Sudan and is associated with social underachievement and the burden on family caregivers is enormous. Accordingly, caregivers of the ostomy patients are at high risk for anxiety, and it is significantly correlated with the patient's QOL, hence there is a need to assess the quality of life for ostomy patients, anxiety, and stress associated with stoma among the local population. Furthermore, there is also a need to understand the demographic and disease-related characteristics which are linked with anxiety, depression, and quality of life.

Because of what was mentioned, counseling, stoma management, and general health education need to be provided to such patients.

\section{Methods:}

Based on the literature, the conceptual framework of our study is that the QOL of ostomy patients is lower than that of the general population and ostomy patients will have a high level of anxiety and depression. The objectives of the study were: to assess the quality of life, levels of anxiety, and depression among Sudanese ostomates using a modified Fecal Incontinence Quality of Life questionnaire (FIQOL) and Hospital Anxiety and Depression Scale (HADS) with special emphasis on assessing any associations between QOL, levels of anxiety and depression with the sociodemographic data like the age, gender, level of education, marital status, occupation, family monthly income, and health insurance. Along with assessing any associations to the stoma surgery-related data and this includes the following: stoma site, type of stoma, stoma shape, illness led to a stoma, contact with other ostomy patients, and if underwent regular nursery care after ostomy surgery. 
The study was conducted in Khartoum state, which is the capital of Sudan, between 2018 and 2019. The patients were seen in outpatient clinics of six hospitals throughout three localities of Khartoum state: Khartoum, Omdurman, and Khartoum North. The patients were consecutive clinical attendees who were currently receiving follow-up check or drug treatment with inclusion criteria of adult (above 18) Sudanese patients and exclusion criteria of patients with psychiatric illness, patients with other major comorbidities, and patients with ostomy less than three-month durations. For each selected participant who refused to participate; the next patient was invited to participate in the study. All methods performed in this study were in accordance with the relevant guidelines and regulations.

The questionnaire was divided into four parts: Sociodemographic data, information about stoma, Quality of life inquiry, and HADS scale.

For the quality of life, Likert scale was used. Each Scale ranged from 1-5, with 1 indicating the lowest and 4 indicating the best functional status of QOL. Scale scores are the average (mean) response to all items on the scale.

For HADS scale, each statement had a score from 0 to 3 which means that a person can score between 0 and 21 for either anxiety or depression, the scale was normal if scored from 0 to 7 , borderline if scored from 8 to 10, and abnormal if scored from 11 to 21. For analysis of data, Statistical Package for Social Sciences software (SPSS) version 25.0 was used. Initially, all information was gathered via questionnaire then coded into variables, reliability for the questionnaire was done by alpha Cronbach and spearman brown coefficients. The normality of data was tested using Shapiro-Wilk test. correlations were done by spearman, subgroup differences by ANOVA, and Mann Whitney tests. A p-value of less than 0.05 was considered statistically significant.

\section{Results:}

Quality of life total score was found to be below the average. Depression scale scores at the average, and religious score account for the worst. There was a strong correlation between the QOL subscales. No significant association between quality of life score and the sociodemographic data (Table 1). Regarding anxiety and depression levels $51.3 \%$ of the participants were normal for anxiety level while $25 \%$ and $23.8 \%$ were borderline and abnormal respectively. Regarding the depression level, the score was $45 \%$ normal, $26.3 \%$ borderline, and $28.8 \%$ abnormal. Neither some significant association nor subgroup differences were found regarding sociodemographic and ostomy-related data (Table 2). 
Table 1

shows the results of one sample (t) test to Judge the levels of Quality of Life among patients at the recent research population $(n=80)$

\begin{tabular}{|llllllll|}
\hline Quality of Life Scales & Mean & SD & Test value & t & Df & $\begin{array}{l}\text { Sig. } \\
\text { 2-tailed }\end{array}$ & Statistical Inference \\
\hline Life - style & 1.96 & .69 & 2.5 & -7.086 & 79 & .001 & Below Average \\
\hline Coping / Behavior & 2.29 & .69 & 2.5 & -2.758 & 79 & .004 & Below Average \\
\hline Dep. / Self p. & 2.41 & .78 & 2.5 & -1.030 & 79 & .153 & At Average \\
\hline Embarrassment & 1.98 & .84 & 2.5 & -5.580 & 79 & .001 & Below Average \\
\hline Religious & 1.84 & .66 & 2.5 & -8.908 & 79 & .001 & Below Average \\
\hline QOL & 2.10 & .42 & 2.5 & -8.678 & 79 & .001 & Below Average \\
\hline
\end{tabular}

Table 2

shows results of t-test for groups to determine the significance of differences on Anxiety and Depression according to patient's gender at ostomy patients $(n=80)$

\begin{tabular}{|c|c|c|c|c|c|c|c|}
\hline \multirow[t]{2}{*}{ Variables } & \multirow[t]{2}{*}{ Levels } & \multirow[t]{2}{*}{$\begin{array}{l}\text { Scores } \\
\text { Range }\end{array}$} & \multirow[t]{2}{*}{ Frequency } & \multirow[t]{2}{*}{$\%$} & \multirow[t]{2}{*}{$\begin{array}{l}\text { Std. } \\
\text { Error }\end{array}$} & \multicolumn{2}{|c|}{$\begin{array}{l}\text { (95\%) confidence } \\
\text { interval }\end{array}$} \\
\hline & & & & & & $\begin{array}{l}\text { Lower } \\
\text { limit }\end{array}$ & $\begin{array}{l}\text { Upper } \\
\text { limit }\end{array}$ \\
\hline \multirow[t]{4}{*}{ Anxiety } & Normal & $0-7$ & 41 & 51.3 & .056 & 40 & 62 \\
\hline & Mild & $8-10$ & 20 & 25.0 & .048 & 16 & 35 \\
\hline & Moderate & $11-16$ & 12 & 15.0 & .040 & 7 & 23 \\
\hline & Severe & $17-21$ & 7 & 8.8 & .032 & 3 & 15 \\
\hline \multirow[t]{3}{*}{ Depression } & Normal & $0-7$ & 36 & 45.0 & .056 & 34 & 56 \\
\hline & Borderline & $8-10$ & 21 & 26.3 & .049 & 17 & 36 \\
\hline & Abnormal & $11-21$ & 23 & 28.8 & .051 & 19 & 39 \\
\hline
\end{tabular}

Using Pearson correlation coefficient, the quality of life subscales were found to be significantly correlated to each other's and within the total sore (Table 3). The lifestyle score was significantly correlated with coping/behavior score ( $\mathrm{p} \rrbracket .002)$ and with the total score ( $\mathrm{p} \rrbracket .001)$. The coping behavior score was also found to be significantly correlated with depression/ self-perception score (p凶.001), embarrassment ( $\mathrm{p} \rrbracket .001)$, and the total score ( $\mathrm{p} \otimes .001)$. The depression/ self-perception score was also found to be correlated with the total score ( $\mathrm{p} \rrbracket .001)$. Embarrassment score in addition to the above correlation it was significantly correlated with the total score (p囚.001), and there was a significant 
negative correlation between it and the religious score ( $\mathrm{p} \otimes .02)$. The religious score in addition to its negative correlation with the embarrassment score ( $\mathrm{p} \otimes .02)$, was also found to be positively correlated with the total scale score (p囚.01).

Table 3

shows the results of Pearson's Correlations in between the five scales of quality of life among ostomy patients at the research population $(n=80)$

\begin{tabular}{|c|c|c|c|c|c|c|}
\hline $\begin{array}{l}\text { Quality of Life } \\
\text { Scales }\end{array}$ & Indicator & $\begin{array}{l}\text { Coping / } \\
\text { Behavior }\end{array}$ & $\begin{array}{l}\text { Dep./Self } \\
\text { p. }\end{array}$ & Embarrassment & Religious & QOL \\
\hline \multirow[t]{2}{*}{ Life - style } & $\begin{array}{l}\text { Coefficient } \\
(r)\end{array}$ & $.312^{* *}$ & .154 & .138 & .135 & $.587^{\star \star}$ \\
\hline & $\begin{array}{l}\text { Sig. (1- } \\
\text { tailed) }\end{array}$ & .002 & .087 & .111 & .116 & .001 \\
\hline \multirow[t]{2}{*}{$\begin{array}{l}\text { Coping / } \\
\text { Behavior }\end{array}$} & $\begin{array}{l}\text { Coefficient } \\
(r)\end{array}$ & & $.455^{\star \star}$ & $.419^{\star *}$ & .005 & $.773^{\star \star}$ \\
\hline & $\begin{array}{l}\text { Sig. }(1- \\
\text { tailed) }\end{array}$ & & .001 & .001 & .483 & .001 \\
\hline \multirow[t]{2}{*}{ Dep. / Self p. } & $\begin{array}{l}\text { Coefficient } \\
\text { (r) }\end{array}$ & & & .174 & -.028 & $.636^{* *}$ \\
\hline & $\begin{array}{l}\text { Sig. }(1- \\
\text { tailed) }\end{array}$ & & & .062 & .402 & .001 \\
\hline \multirow[t]{2}{*}{ Embarrassment } & $\begin{array}{l}\text { Coefficient } \\
(r)\end{array}$ & & & & $-.229^{\star}$ & $.577^{\star \star}$ \\
\hline & $\begin{array}{l}\text { Sig. }(1- \\
\text { tailed) }\end{array}$ & & & & .020 & .001 \\
\hline \multirow[t]{2}{*}{ Religious } & $\begin{array}{l}\text { Coefficient } \\
(r)\end{array}$ & & & & & $.259^{\star \star}$ \\
\hline & $\begin{array}{l}\text { Sig. (1- } \\
\text { tailed) }\end{array}$ & & & & & .010 \\
\hline \multicolumn{7}{|c|}{ ** Correlation is significant at the 0.01 level (1-tailed). } \\
\hline \multicolumn{7}{|c|}{ * Correlation is significant at the 0.05 level (1-tailed). } \\
\hline
\end{tabular}

Quality of life subscales and the total score were tested for correlation with age, educational level, family income, and insurance status using spearman's correlation and no other correlation was found (Table 4). 
Table 4

shows the results of Spearman's Correlations between the scales of quality of life with age, education, family monthly income and having health insurance among ostomy patients at the research population $(n=80)$

\begin{tabular}{|c|c|c|c|c|}
\hline Quality of Life Scales & Indicator & Age & Education Level & Family income \\
\hline \multirow[t]{2}{*}{ Life-style } & Coefficient ( $r$ ) & -.075 & .092 & -.020 \\
\hline & Sig. (1-tailed) & .253 & .209 & .432 \\
\hline \multirow[t]{2}{*}{ Coping / Behavior } & Coefficient (r) & -.075 & .060 & -.047 \\
\hline & Sig. (1-tailed) & .254 & .299 & .340 \\
\hline \multirow[t]{2}{*}{ Dep. / Self p. } & Coefficient (r) & -.050 & -.109 & -.131 \\
\hline & Sig. (1-tailed) & .330 & .168 & .124 \\
\hline \multirow[t]{2}{*}{ Embarrassment } & Coefficient (r) & .117 & -.077 & -.010 \\
\hline & Sig. (1-tailed) & .151 & .250 & .464 \\
\hline \multirow[t]{2}{*}{ Religious } & Coefficient (r) & .032 & -.023 & .094 \\
\hline & Sig. (1-tailed) & .390 & .420 & .203 \\
\hline \multirow[t]{2}{*}{ QOL } & Coefficient ( $r$ ) & -.016 & .029 & .001 \\
\hline & Sig. (1-tailed) & .443 & .401 & .496 \\
\hline \multicolumn{5}{|c|}{ ** Correlation is significant at the 0.01 level (1-tailed). } \\
\hline \multicolumn{5}{|c|}{ * Correlation is significant at the 0.05 level (1-tailed) } \\
\hline
\end{tabular}

Levels of anxiety and depression were tested for correlation with age, educational level, family income using spearman's correlation and no significant correlation was found (Table 5). 
Table 5

shows the results of Spearman's Correlations between the scales of Anxiety and Depression with age, education, and family monthly income among ostomy patients at the research population $(n=80)$

\begin{tabular}{|lllll|}
\hline Variables & Indicator & Age & Education Level & Family income \\
\hline \multirow{2}{*}{ Anxiety } & Coefficient $(r)$ & -.175 & -.051 & -.016 \\
\cline { 2 - 6 } & Sig. (1-tailed) & .060 & .325 & .442 \\
\hline \multirow{2}{*}{ Depression } & Coefficient $(r)$ & -.031 & -.034 & .118 \\
\cline { 2 - 5 } & Sig. (1-tailed) & .392 & .383 & .148 \\
\hline \multirow{2}{*}{$*$ Correlation is significant at the 0.01 level (1-tailed). } \\
\hline \multirow{2}{*}{ * Correlation is significant at the 0.05 level (1-tailed). } \\
\hline
\end{tabular}

\section{Discussion:}

Colostomy and ileostomy are essential surgical procedures that may be temporal or permanent. In Many occasions, the surgeon may need to perform them for a particular reason. A colostomy is usually indicated in situations like rectal or colonic tumors, rectovesical or rectovaginal fistulae, and rectal or bowel injury or perforation.

Despite being mandatory procedures on many occasions, colostomy and ileostomy are never free from complications. In addition to general surgery complications like wound infection, bleeding, retraction, prolapse, etc, we must not forget the psychological effects of a stoma. Thus, the main aim of this study was to assess the quality of life, levels of anxiety, and depression among Sudanese patients with a surgical stoma in Khartoum state, Sudan 2018-2019.

A total of 100 patients were approached in the study; however, only 80 participants took part in the study, resulting in an $80 \%$ response rate, this response rate is significantly high when compared with the other studies. For example response rate was $59 \%$ for a study conducted in California, $49 \%$ for United States study, and $39 \%$ for an Irish study ${ }^{(16-18)}$.

The age was found to be equally distributed between three categories with 19 years as minimum age and 65 years as the maximum. The majority of participants were males who accounted for $61.3 \%$ of participants while females accounted for only $38.8 \%$. This consists with other similar studies where males accounted for the majority $(21,22,24)$. This is mainly because colorectal cancer -which is the commonest cause for ostomy surgery- is common among males despite equal risk factors to females. This is in comparison to an Irish study done on ileostomy association, the majority of the respondents were female $60.5 \%$ indicating that IBD commonly runs among females ${ }^{(17)}$. 
A considerable percentage of the patients lost their jobs after stoma operation. The job percentage dropped from $66.3-31.3 \%$. This might be attributable to the fact that stoma affects the physical competence of the patients and the ability to adapt to the external environment. This corresponds to a study done in the Netherlands which revealed that social functioning self-efficacy had a great significance, a low adaptation level correlates positively with many stoma problems ${ }^{(26)}$.

Regarding the educational level of participants, higher educational levels accounted less than high school educational level participants and illiterate participants.

For the majority of the participants who had a permanent colostomy, colorectal cancer was the most common diagnosis that led to stoma. These findings agree with other studies $(16,17,22)$. The majority of the participants underwent a regular stoma nursery at the hospital before discharge (60\%). Yet $40 \%$ of patients were found to have a direct family member who provides care to their ostomy immediately after the operation. This is a high percentage to be taken in mind as many studies have revealed the importance of precise nursery care for ostomates ${ }^{(28,29)}$. On the other hand, the majority of the participants had no contact with other ostomy patients (70\%) and this is because support groups as a tool for psychotherapy are lacking here in Sudan with a shortage of doctors trained to meet the national mental health needs, yet support groups are a very strong tool for intervention in ostomy patients and many studies have revealed this ${ }^{(30,31)}$.

Patients' quality of life scores were low with a mean of 2.10 (below average), which corresponds with an Egyptian study where the mean was found to be $2.14{ }^{(24)}$. Similarly in a study in Pakistan, the rescore 79.63 fell to $55.79^{(22)}$. A comparative study in Denmark stated that 22 out of 27 variables were poorer in ostomates compared to non-ostomates ${ }^{(20)}$. An Indian study revealed the same ${ }^{(32)}$. Yet this result is significantly low when compared with the other studies of Europe and California $(16,19)$.

Regarding the subscales, the lifestyle score was below the average of 1.96 , this indicates ostomates have some problems in adjusting and adapting their lifestyle after stoma operation. This also indicates that impeding in their social life and activity is very poor, and this finding corresponds to many studies $(17,20)$. These results are low if compared to an Egyptian study that found lifestyle to be $2.21^{(24)}$.

Regarding the coping/behavior score was found to be 2.29 although it is below the average, the score is high when compared with the other quality of life subscales and it is also high when compared to an Egyptian coping/behavior score of $2.06^{(24)}$. An Irish study found that coping /behavior regarding the diet had been changed by $45 \%$ after stoma operation ${ }^{(17)}$.

Depression/self-perception scale scored 2.41 this result considers at average and the score was found to be the best score if compared to the other quality of life subscales and its high if compared to the Egyptian study 2.38 (below the average) ${ }^{(24)}$. This could be explained by the fact that Sudan's environment is very domestic to accept ostomy patients at least to the level that secures them from depression, this is very true if compared to other western studies $(17,20)$. 
On the other hand, the embarrassment scale was found to be below the average of 1.98 and it is low if compared with other quality of life subscales but higher than the Egyptian score of $1.87^{(24)}$. A worth finding to mention is that the embarrassment score especially the sexual and self-image domains had always been low and statistically significant in a lot of studies $(17,18,20,23)$.

The lowest score found was the religious scale score and it is even low if compared with the Egyptian score of $2.18^{(24)}$. This raises an essential issue that ostomates were not aware of their religious legitimate excuse offered in such a situation and this is very clear during the data collection process. Yet many studies revealed that stoma adversely affects the religious aspects of the Muslim population and the spiritual QOL of all populations $(22,33,34)$.

The lifestyle score was significantly correlated with coping/behavior score (pष.002) and with the total score ( $\mathrm{p} \varangle .001)$, this was a positive correlation meaning that when lifestyle scale score increases the score of coping behavior increase, this corresponds with the Egyptian study but unlike the Egyptian study no correlation was found with the depression, embarrassment and religious scales ${ }^{(24)}$.

The coping behavior score was also found to be significantly positively correlated with depression/ self-

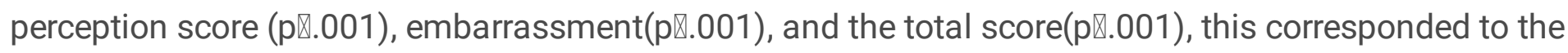
Egyptian study but unlike it, no correlation was found with the religious scale ${ }^{(24)}$.

The depression/ self-perception score was found to be negatively correlated to the religious scale meaning that when the religious score increases the depression will decrease but this was not significant. On the other hand, depression scale score was significantly positively correlated to the total quality of life score $(\mathrm{p} \rrbracket .001)$.

Embarrassment score in addition to the above correlation was significantly correlated with the total score

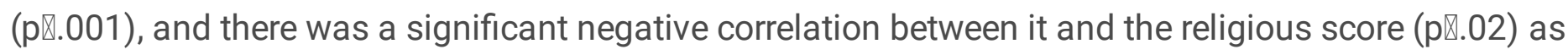
opposed to the Egyptian study which revealed a significant positive correlation between the embarrassment and the religious scale score ${ }^{(24)}$.

The religious score in addition to its negative correlation with the embarrassment score (pख.02), was also found to be positively correlated with the total scale score $(\mathrm{p} \rrbracket .01)$.

No significant differences were observed for age, gender, stoma history, or marital status. Age, gender, stoma history, and marital status were found independently related to the quality of life in stoma patients.

No association was found between ages, education, family income, and the total quality of life total and subscales scores. This corresponds to the Egyptian study but opposes other studies $(17,24,35)$.

Another Egyptian study revealed that gender has a high statistical significance with the sexual and psychological alteration ${ }^{(13)}$. Nevertheless, an Indian study revealed that gender has no significant correlation with the quality of life ${ }^{(32)}$. 
For anxiety, $23.8 \%$ were found to be abnormal, $25 \%$ borderline and $7 \%$ were severely anxious. For depression, the situation was worse with $28.8 \%$ abnormal and $26.3 \%$ borderline. These results correspond to many other studies $(1,12,20,25,27)$.

No significant differences were observed for gender, age, gender, stoma history, or marital status. Age, gender, stoma history, and marital status were found independently related to anxiety and depression levels in stoma patients.

Age, educational level, and income were found to be non-associated with neither anxiety level nor depression level this corresponded to a study done in Pakistan which revealed that anxiety level was not significantly associated with gender, age, type, and disease led to stoma ${ }^{(22)}$.

\section{Conclusions:}

More attention is needed for ostomates regarding their poor quality of life, high levels of depression, and anxiety. Promoting health and rehabilitation is specifically directed at meeting the real needs of this group.

It is better to establish an ostomy support society among different states in Sudan as this will pour for the well-being of the patients and their families. Addressing the religious legitimization for our ostomates should be focused on and mentioned in the counseling process. Training special nurses to take care of ostomates as the care provided for ostomates was found to be a predictor for their good quality of life.

\section{Abbreviations:}

QOL: Quality of life.

FIQOL: Fecal Incontinence Quality of Life questionnaire

HADS: Hospital Anxiety and Depression Scale

IBD: Inflammatory bowel disease.

\section{Declarations:}

\section{Authors' contributions}

All authors attest that they meet the criteria for authorship and equally contributed to the preparation of this manuscript. R.M. and A.Y. did the data collection. K.M. and M.A. did the analysis. M.A., R.M., and A.Y. wrote the main manuscript text, KM was responsible for editing and supervision. All authors read and approved the final manuscript.

\section{Funding}


This study was not funded.

\section{Availability of data and materials}

The data that support the findings of this study are available from the corresponding author upon reasonable request.

\section{Ethics approval and consent to participate}

Ethical approval from the ethical committee of the Faculty of Medicine - University of Khartoum was obtained, and we confirm that all methods were performed in accordance with the relevant guidelines and regulations.

\section{Consent for publication}

Informed written consent for publication was obtained from all patients.

\section{Competing interest}

None of the authors has any competing interests.

\section{Acknowledgments}

Not applicable.

\section{References:}

1. Khan NA, Rehman A, Rashid N, Mughal S, Memon AS. Patt erns of anxiety among patients with Stoma and its determinants: A single center experience Abstract: 2015;31(2):101-6.

2. Saunders RN, Hemingway D. Intestinal stomas. Surgery (Oxford). 2008 Aug 1;26(8):347-51.

3. Devlin HB. Colostomy. Indications, management and complications. Annals of the Royal College of Surgeons of England. 1973 Jun;52(6):392.

4. Kelly SR, Shashidharan M, Borwell B, Tromans AM, Finnis D, Grundy DJ. The role of intestinal stoma in patients with spinal cord injury. 1999;211-4.

5. Shaffy S, Das K, Gupta R. Physical, nutritional and sexual problems experienced by the patients with colostomy/ileostomy: A qualitative study. Nurs Midwifery Res [Internet]. 2012;(3):210-22. Available from: http://medind.nic.in/nad/t12/i3/nadt12i3p210.pdf

6. Mahjoubi B, Moghimi A, Mirzaei R, Bijari A. Evaluation of the end colostomy complications and the risk factors influencing them in Iranian patients. 2005;582-7.

7. Surgery D, Care S, Hospital RG. Complications and mortality following stoma formation. 2005;42731. 
8. White CA, Unwin JC. Post-operative adjustment to surgery resulting in the formation of a stoma: The importance of stoma-related cognitions. 1998;85-93.

9. Bekkers MJTM. Psychosocial Adaptation to Stoma St gery: A Review. 1995;18(1).

10. Krouse RS, Grant M, Rawl SM, Mohler MJ, Baldwin CM, Joel S, et al. Coping and acceptance: The greatest challenge for veterans with. 2009;66:227-33.

11. Kiliç E, Taycan O, I AKB, Özmen M. The E ff ect of Permanent Ostomy on Body Image, Self-Esteem, Marital Adjustment, and Sexual Func oning. 2007;18(4):1-8.

12. Tseng $\mathrm{H}$, Wang $\mathrm{H}$, Hsu $\mathrm{Y}$, Weng W. F ACTORS R ELATED TO $S$ TRESS IN O UTPATIENTS. Kaohsiung $J$ Med Sci [Internet]. Elsevier; 2004;20(2):70-6. Available from: http://dx.doi.org/10.1016/S1607551X(09)70087-7

13. El-rahman SKA, Ali SAA. Assessment of Embarrassments to Safety Aspects of Life of Patients after Performing Colostomy Operations, in Two Egyptian Societies. 2011;41(4).

14. Ventegodt S, Merrick J, Andersen NJ. Quality of Life Theory I. The IQOL Theory: An Integrative Theory of the Global Quality of Life Concept. 2003;1030-40.

15. Hornquist JO. Quality of Life: Concept and Assessment. 2016;69-79.

16. Dean G, Ph D, Nelson R, Ph D, Chu D. Quality of Life Outcomes in 599 Cancer and Non-Cancer Patients with Colostomies. 2007;87:79-87.

17. Davidson F. Quality of life, wellbeing and care needs of Irish ostomates. 2016;(August).

18. Symms MR, Rawl SM, Grant M, Wendel CS, Coons SJ, Hickey S, et al. Sexual Health and Quality of Life Among Male Veterans With Intestinal Ostomies. 2008;46202.

19. Marquis P, Marrel A, Jambon B. Quality of life in patients with stomas: the Montreux Study. Ostomy wound management. 2003 Feb 1;49(2):48-55.

20. Karlsen R V, Boesen EH. Quality of life of Danish colorectal cancer patients with and without a stoma. 2006;

21. Kement M, Gezen C, Aydin H, Haksal M, Can U. A Descriptive Survey Study to Evaluate the Relationship Between Socio-demographic Factors and Quality of Life in Patients with a Permanent Colostomy. 2014;(October).

22. Ahmad M, Jamal S, Ahmad N. Quality of Life Assessment in Patients with Stoma in Muslim Population. :222-7.

23. Vinluan KMAEAASAJM. RESEARCH ARTICLE A cross-sectional assessment of quality of life of colorectal cancer patients in Saudi Arabia. Clin Transl Oncol. Springer Milan; 2016;18(2):144-52.

24. Hussein AM, Fadl SA. Quality of life in Egyptian stoma patients. Egypt J Surg. 2001 Jul;20(3):597607.

25. Cotrim H. Impact of colorectal cancer on patient and family: Implications for care. 2008;217-26.

26. Bekkers MJTM, Knippenberg FCEVAN, Borne HWVANDEN, Utrecht H. Prospective Evaluation of Psychosocial Adaptation to Stoma Surgery: The Role of Self-Efficacy. 1996;191:183-91. 
27. Jiat R, Siah C, He H. Stressors Relating to Patient Psychological Health Following Stoma Surgery: An Integrated Literature Review. 2005;

28. Copyright D. Should WOC nurses measure health-related quality of life in patients undergoing intestinal ostomy surgery? 2019;1-3.

29. Care C. The Braden Scale for Predicting Pressure Sore Risk. 2005;32(2).

30. Aboaja A, Myles P, Hughes P. Mental health e-supervision for primary care doctors in Sudan using the WHO mhGAP Intervention Guide. 2015;12(May):16-9.

31. Dinç L. Effects of planned group interactions on the social adaptation of individuals with an intestinal stoma: A quantitative study individuals with an intestinal stoma: a quantitative study. 2014;(May 2016).

32. Roshini AP, Sunny A, Rozario AP, Sunny A. Quality of life assessment in stoma patients in a tertiary care hospital in South India: a cross- sectional study. 2017;4(6):2037-41.

33. Cavdar I. Religious Worship in Patients with Abdominal Stoma: Praying and. 2013;6(3):516-21.

34. Baldwin CM, Grant M, Wendel C, Roudebush RL, Medical VA. Influence of Intestinal Stoma on Spiritual Quality of Life of U. S. Veterans. 2008;1-10.

35. Care O. in Taiwanese Patients With Colorectal Cancer and a Colostomy. 2012;39(April):161-9. 